\section{To follow a flow}

Flow Visualisation. By Wolfgang Merzkirch. Pp. viii +250. (Academic: New York and London, October 1974.) $\$ 26.00 ; £ 12.50$.

THE need for reliable and accurate methods for rendering fluid flows visible arises in a wide variety of situations in aerodynamics, chemical engincering and fundamental experimental studies in fluid dynamics. Many different techniques have been developed over the ycars and major advances in the subject have occurred quite recently. For that reason alone there has been a need for a book which collects together all these techniques and brings the subject up to date. This book fills the need adequately. In an exhaustive survey the author describes, with the appropriate theoretical background, the methods from many fields, and he identifies the conditions and parameter ranges under which each method is applicable.

Merzkirch divides the subject into three classes: over half of the book is given over to the classification which is concerned with the various optical arrangements available for obtaining both qualitative and quantitative information from fluid flows. This classification, which is headed rather loosely "Optical methods for compressible flows" (even though, in 1act, several of these methods have been successfully used in incompressible flow situationsschlieren systems in salt stratified fluids, for example) describes in detail techniques such as shadowgraph and schlieren arrangements which are based on the change in refractive index of a fluid as a function of density. There are particularly interesting contributions on holographic flow visualisation and the laser-Doppler anemometer, though it is doubtful whether its inclusion in this book is strictly justified.

The second division comprises techniques which rely on the addition to the flow of foreign material such as dyc. Attention is given to the basic criterion that the flow should not be disturbed by either the mode of injection or by the material itself, and a series of empirical rules, ranges of validity and necessary corrections are given for the various methods. This section, which is descriptive in character, contains useful information on the more recent innovations such as temperature-sensitive paints, liquid crystals and flash photolysis, as well as coverage of the more traditional methods.

The remainder of the book is taken up with a discussion of special problems and techniques and a third classification headed "Flow field marking by heat and energy addition". The methods described in the book cover a very wide range but are confined essentially to laboratery scale flows. For completcness it could have included some of the special techniques used in larger scale field observations (estuary flows or oceanographic phenomena, for example).

Nevertheless, the book is well written and contains a large number of excellent photographic illustrations, and it will be very useful to expcrimentalists working in many branches of fluid dynamics. P. A. Davies

\section{Life time of an organism}

Living Clocks in the Animal World. (A Monograph in American Lectures in Environmental Studies.) By Miriam F. Bennett. Pp. xiii +221 . (Charles C. Thoms: Springfield, June 1974.) \$11.75.

CIRCADIAN and other biological rhythms are attracting increasing attention every year. Strictly speaking, however, we still do not know how their extraordinary 'clock' properties are achieved. The majority of investigators, myself included, consider that the timing of circadian rhythms is derived from the chemistry and physics of the cell or organism. At least one laboratory, however, led by Professor F. A. Brown, believes that the timing is provided by "subtle geophysical factors" associated with the solar day, and, incidentally, not excluded in most experiments.

The author of this small volume has been one of Brown's associates, and when I opened the book I expected to find that she pressed the second of these views. She presents both cases quite fairly, however, and interprets many of the phenomena in endogenous terms. She points out that the 'exogenous school' does recognise that organisms are "cquipped with cellular clocks", and that the "endogenous school' recognises that environmental variables, particularly changes in light intensity and temperature, can modulate overt rhythms in a manner which is distinct from their rôles as entraining agents. She considers, perhaps correctly, that a "spectrum" of clocks from "purely" endogenous to "purely" exogenous exists in the animal world.

Her material is, however, limited to those groups which she knows best, and she ignores almost totally the work done on birds, mammals and insects, which has provided most of our knowledge on circadian systems. For this reason, I would not recommend it to any of my students. D. S. Saunders
New from Addison-Wesley Advanced Book Program

\section{FRONTIERS IN PHYSICS}

A Lecture Note and Reprint Series

DAVID PINES, Series Editor

No. 43:

RONALD C. DAVIDSON

University of Maryland

Theory of Nonneutral Plasmas*

This volume is relevant to several diverse areas of physics that deal with plasma systems with large self fields (collective-effect accelerators; relativistic electron bcams; magnetically-confined nonneutral plasmas; experiments for stripping of heavy ions). 1974, xvi, 204 pp., illus.

hardbd. ISBN $0-805-32345-7, £ 8.25$

paperbd. ISBN 0-805-32346-5, £4.70

No. 44:

S. DONIACH Stanford University

E. H. SONDHEIMER University of London

Green's Functions for

Solid State Physicists*

Green's function methods of quantum field theory have become recognized as a powerful mathematical tool for studying the complex interacting systems of solid state physics. This volume shows the methods in action jllustrating how mathematics - in the form of the Green's function in the complex energy plane-accounts for the physical effects (level shifts, damping, instabilities) characteristic of interacting systems. Keeping the reader in contact with the real problems, the book concentrates on general physical principles and includes introductions to topics of current research interest without detailed discussions of experiments

1974, xx, 268 pp., illus.

hardbd. ISBN 0-805-32394- 5, £10.45

paperbd. ISBN 0 - 805-32395-3, £6.90

No. 45 :

P. H. FRAMPTON Syracuse University

Dual Resonance Models*

Here is the comprehensive account of a new, important approach to strong interaction theory. The volume contains a clear and systematic treatment of dual resonance models proceeding from an introduction of basic principles to discussions of recent results in the literature.

1974, xxiv, 452 pp., illus.

hardbd. ISBN 0-805-32580-8, £12.40 paperbd. ISBN $0-805-32581-6, £ 8.00$

*W. A. Benjamin, Inc, title

Detailed leaflet on Series available from Publisher.

Addison-Wesley Publishers, Ltd.

West End House Advanced Book Program 11 Hills Place Reading, Mass. 01867 London U.S.A. 